\title{
THYROID FUNCTION ABNORMALITIES IN CHRONIC LIVER DISEASES
}

\author{
Navaneeth Puthiyedath Govindan1, Mridulkumar Kannath ${ }^{2}$
}

${ }_{1}^{1}$ Senior Resident, Department of General Medicine, Government Medical College, Kottayam, Kerala, India.

${ }_{2}^{2}$ Associate Professor, Department of General Medicine, Government Medical College, Kottayam, Kerala, India.

\section{BACKGROUND}

ABSTRACT

A complex relationship exists between the thyroid gland and the liver in both health and disease. Many studies have been carried out on liver disease patients assessing their thyroid status, mostly in European countries. Most of these studies are limited by the number of patients in these studies. This study tries to find out the relationship between thyroid function and chronic liver disease in a tertiary care hospital in India.

Aim- To study the thyroid function abnormalities in chronic liver disease and its relationship with liver function.

\section{MATERIALS AND METHODS}

After obtaining clearance from the Institutional Review Board, this hospital-based cross-sectional study was conducted in patients admitted in the ward under the Department of General Medicine. A total of 150 subjects were selected after explaining the purpose of the study and the procedure in detail and after obtaining their consent in written format. Data collection was done by history, clinical examination and investigations. With physical examination aided by abdominal imaging, patients who had ascites were graded into mild, moderate and severe refractory ascites. Hepatic encephalopathy was graded into grade 0 to 4 according to We st Haven criteria.

\section{RESULTS}

$24.6 \%$ of the study population showed abnormalities in thyroid function tests. The commonest was sick euthyroid syndrome in $18 \%$ of patients. Subclinical hypothyroidism was present in $4.7 \%$ of patients. Thyroid hormone levels had significant correlation with various liver function indices. Serum levels of total T3 and free T3 had significant positive correlation with serum albumin level and negative correlation with serum bilirubin and INR value. Free T4 had a weak negative correlation with serum bilirubin. Serum T3 and Free T3 were found to be decreased in patients with hepatic encephalopathy and ascites according to the severity. When severity of liver dysfunction was assessed using Child-Pugh score, it was found that there was statistically significant decrease in serum T3 and FT3 levels as the severity of liver dysfunction increased.

\section{CONCLUSION}

Chronic liver diseases were associated with abnormalities in thyroid function tests, although most of the patients remained clinically euthyroid. Serum T3 and FT3 levels had an inverse correlation with the severity of liver dysfunction.

\section{KEY WORDS}

Chronic Liver Disease, Thyroid Function Abnormalities.

HOW TO CITE THIS ARTICLE: Govindan NP, Kannath M. Thyroid function abnormalities in chronic liver diseases. J. Evolution Med. Dent. Sci. 2018;7(42):4539-4544, DOI: $10.14260 /$ jemds/2018/1013

\section{BACKGROUND}

Chronic liver disease represents a series of liver disorders of varying causes and severity, in which hepatic inflammation and necrosis continue for at least 6 months. Liver plays an important role in thyroid hormone metabolism. The association between chronic liver diseases and thyroid dysfunctions has often been reported. The most consistent ones reported in chronic liver disease is low serum T3 and free T3 level. This reflects a decreased type 1 deiodinase activity in hepatic tissue in chronic liver diseases, which converts T4 to T3. Different studies demonstrated that fall in T3 and free T3 level parallel with the severity of liver dysfunction.

'Financial or Other Competing Interest': None.

Submission 08-09-2018, Peer Review 02-10-2018,

Acceptance 08-10-2018, Published 15-10-2018.

Corresponding Author:

Mridulkumar Kannath,

Shreyas Mudappattuthazham,

Karuvissery P. O., Kozhikode-673010, Kerala, India.

E-mail: mridulkumar.k@gmail.com

DOI: $10.14260 /$ jemds $/ 2018 / 1013$
Thyroid hormone is associated with basal metabolic rate, and low total and free T3 levels may reflect adaptive hypothyroid state, which may help to preserve hepatocytes and liver function by reducing the basal metabolic rate. Occurrence of hypothyroidism in cirrhotic patients has been shown to be associated with a biochemical improvement in liver function and decreased rate of decompensation in cirrhosis.

\section{Objectives}

To study the thyroid function abnormalities in chronic liver diseases and its relation with liver function.

\section{Study Design}

A cross-sectional study.

\section{Period and Duration of Study}

12 months from $16 / 11 / 2015$ to $15 / 11 / 2016$

\section{Study Location}

This study was conducted in the Department of General Medicine, Kottayam Medical College, Kerala. 


\section{Study Population}

The study population were the patients with chronic liver diseases admitted in the General Medicine Ward of Kottayam Medical College.

\section{Sample Size}

Sample size is calculated by the formula-

$\mathrm{N}=\frac{\left(\mathrm{Z}_{1-\alpha / 2}\right)^{2} \mathrm{P}(1-\mathrm{P})}{\mathrm{d}^{2}}$

Where,

$\mathrm{Z}_{1-\alpha / 2}=1.96$ for at $5 \%$ level of significance.

$\mathrm{P}=$ anticipated population proportion of factor under study

$\mathrm{D}=$ Absolute precision, 6

According to a study conducted by Sandeep Kharb et al, thyroid dysfunction was present in $16 \%$ of patients with liver disease. ${ }^{1}$ Based on this fact ' $p$ ' was taken as $16 \%$. Substituting these values in the above formula, $\mathrm{N}$ is calculated as 149.3 rounded off to 150 patients.

\section{Inclusion Criteria}

All patients admitted in medicine wards with chronic liver diseases. Diagnosis of chronic liver disease was based on clinical grounds, impaired liver function tests and ultrasonographic features consistent with chronic liver disease.

\section{Exclusion Criteria}

1. Patients with preexisting thyroid disorder, chronic renal failure, congestive heart failure, malignancy.

2. Patients on medications known to cause TFT derangement.

\section{MATERIALS AND METHODS}

After obtaining clearance from the Institutional Review Board, this hospital-based cross-sectional study was conducted in inpatients of the Department of General Medicine. A total of 150 subjects were selected after explaining the purpose of the study and procedure in detail and after obtaining their consent. Data collection was done by history taking, clinical examination and investigations. With physical examination aided by imaging, patients who had ascites were graded into mild, moderate and severe refractory ascites. Hepatic encephalopathy was graded into grade 0 to 4 according to West Haven criteria.

Serum bilirubin, SGOT, SGPT, albumin, ALP, prothrombin time and value were estimated.

TFT including TSH, T3, T4, FT3 and FT4 were estimated using chemiluminescence method.

\section{Statistical Analysis}

Data from the study case sheets were entered in Microsoft Excel. SPSS version 20.0 was used for data analysis. Continuous variables were described by Mean, SD, Minimum and Maximum. Qualitative variables were described by percentage distribution between groups. Parametric data were expressed as mean values \pm standard deviation (SD) and categorical variables as percentages. Categorical data were analysed by Chi-square tests for statistical significance. The Pearson's correlation coefficient was calculated for continuous variables to find out the relation between them. ANOVA was used to calculate $P$ value in comparison of more than two continuous variables. A $\mathrm{P}$ value $<0.05$ was considered statistically significant.

\section{RESULTS}

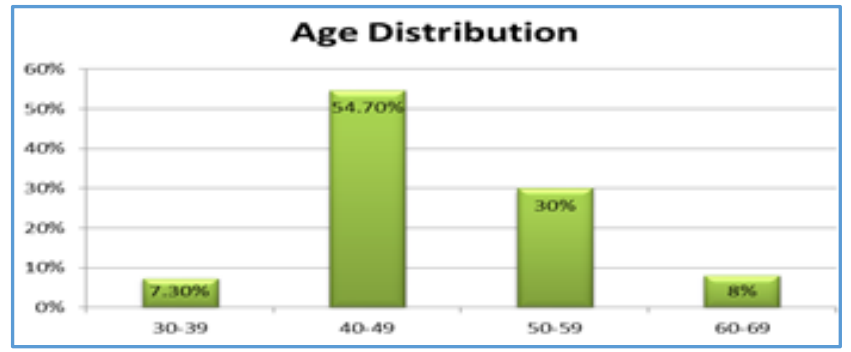

Figure 1

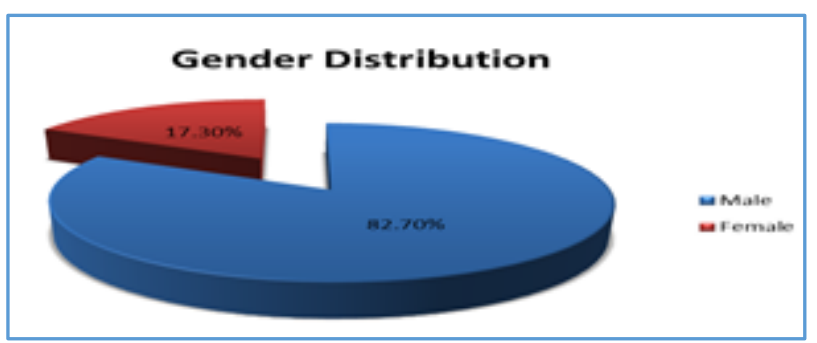

Figure 2

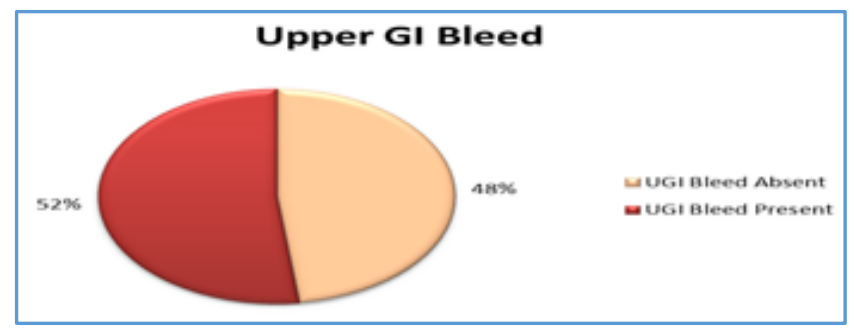

Figure 3

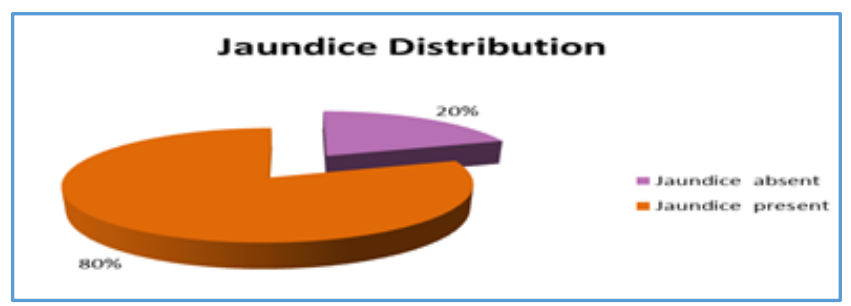

Figure 4

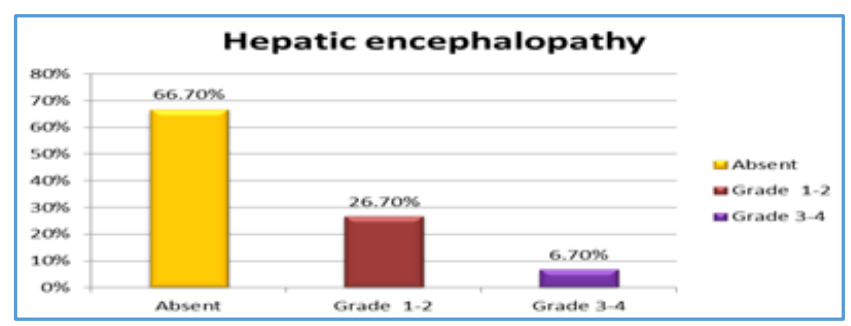

Figure 5

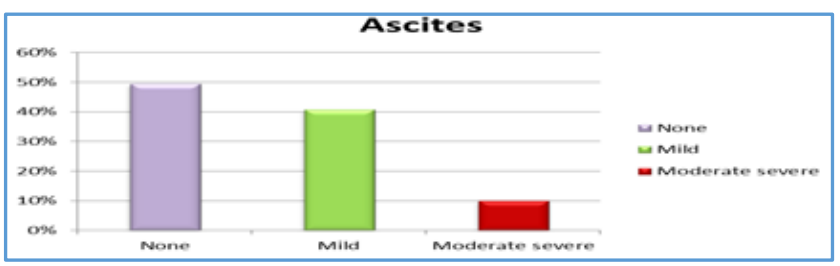

Figure 6 


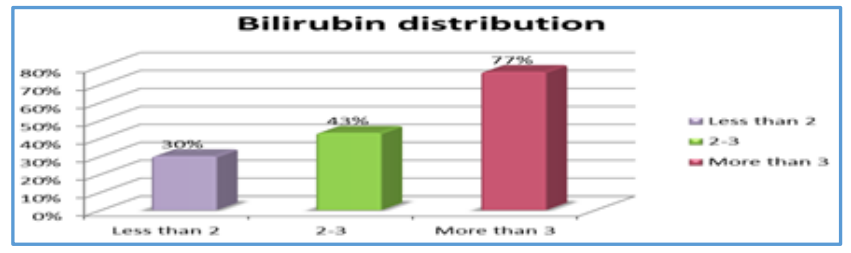

Figure 7

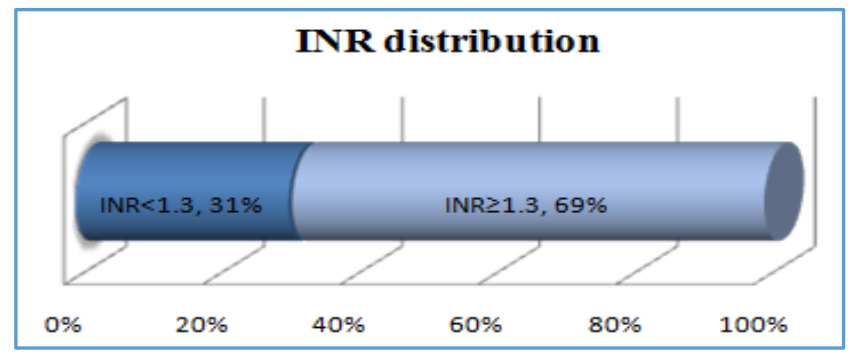

Figure 8

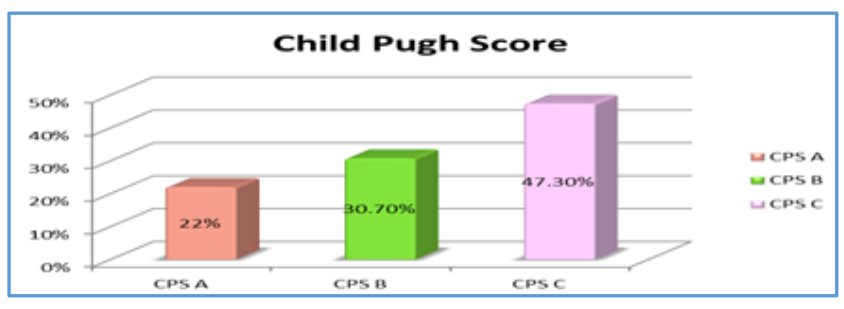

Figure 9

\begin{tabular}{|c|c|c|c|c|}
\hline & Minimum & Maximum & Mean & $\begin{array}{c}\text { Standard } \\
\text { Deviation }\end{array}$ \\
\hline TB & 1.1 & 10.8 & 4.14 & 2.47 \\
\hline ALB & 2.3 & 4.0 & 3.21 & 0.47 \\
\hline SGOT & 22 & 280 & 60.94 & 38.42 \\
\hline SGPT & 14 & 198 & 43.26 & 23.95 \\
\hline ALP & 48 & 238 & 105.5 & 31.17 \\
\hline PT & 14 & 36.2 & 22.6 & 5.41 \\
\hline INR & 1.0 & 2.75 & 1.611 & 0.39 \\
\hline \multicolumn{6}{|c|}{ Table 1. Liver Function Tests } \\
\hline
\end{tabular}

\begin{tabular}{|c|c|c|c|c|}
\hline & Minimum & Maximum & Mean & $\begin{array}{c}\text { Standard } \\
\text { Deviation }\end{array}$ \\
\hline TSH & 0.20 & 18.6 & 2.78 & 2.05 \\
\hline T3 & 0.36 & 2.04 & 1.02 & 0.31 \\
\hline T4 & 3.07 & 10.80 & 7.69 & 1.45 \\
\hline FT3 & 1.52 & 4.26 & 2.78 & 0.52 \\
\hline FT4 & 0.56 & 2.14 & 0.99 & 0.20 \\
\hline \multicolumn{5}{|c|}{ Table 2. Thyroid Function Tests } \\
\hline
\end{tabular}

\begin{tabular}{|c|c|c|c|}
\hline & Liver Size & Spleen Size & Portal Vein Size \\
\hline Mean & $14.97 \pm 1.28$ & $11.03 \pm 0.80$ & $12.06 \pm 1.01$ \\
\hline \multicolumn{4}{|c|}{ Table 3. USG Findings } \\
\hline
\end{tabular}

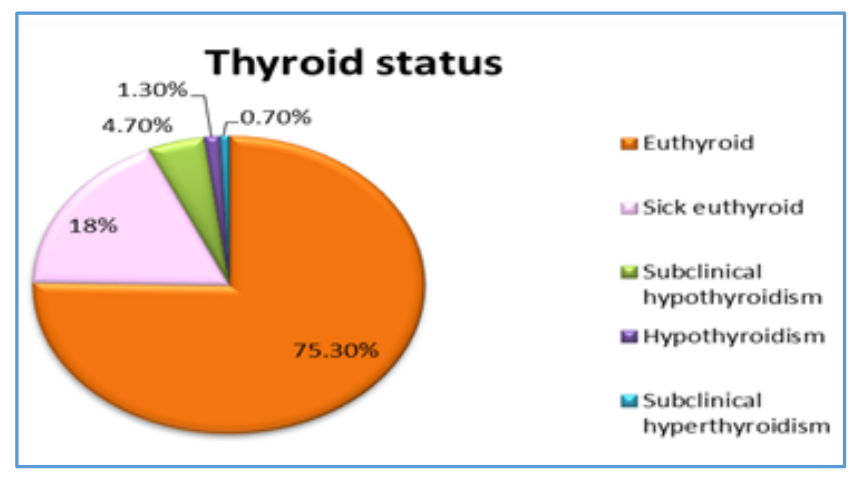

Figure 10
Correlation between Thyroid Function and Liver Function

The correlation between various thyroid function variables and liver function variables was calculated using Pearson's coefficient of correlation method.

\section{The Results are shown in below table}

\begin{tabular}{|c|c|c|c|c|c|c|c|}
\hline & TB & ALB & SGOT & SGPT & ALP & INR & CPS \\
\hline \multirow{2}{*}{ TSH } & 0.083 & 0.073 & -0.076 & 0.006 & 0.076 & -0.043 & 0.017 \\
\hline & 0.313 & 0.375 & 0.353 & 0.939 & 0.354 & 0.598 & 0.841 \\
\hline \multirow{2}{*}{ T3 } & $-0.440^{* *}$ & $0.581^{* *}$ & 0.001 & 0.034 & 0.027 & $-0.348^{* *}$ & $-0.556^{* *}$ \\
\hline & 0.001 & 0.001 & 0.986 & 0.681 & 0.739 & 0.001 & 0.001 \\
\hline \multirow{2}{*}{$\mathrm{T} 4$} & -0.151 & 0.123 & -0.063 & -0.137 & & -0.085 & -0.104 \\
\hline & $0 \Omega 66$ & 32 & 0.443 & 0.095 & $\begin{array}{l}0.051 \\
0.538\end{array}$ & 0.302 & 0.205 \\
\hline \multirow{2}{*}{ FT3 } & $-0.537^{* *}$ & $0.596^{* *}$ & 0.153 & 0.159 & 0,039 & $-0.433^{* *}$ & $-0.658^{* *}$ \\
\hline & 0.001 & 0.001 & 0.062 & 0.052 & $\begin{array}{l}0.039 \\
0.631\end{array}$ & 0.001 & 0.001 \\
\hline \multirow{2}{*}{ FT4 } & $\mid-0.162^{*}$ & 0.076 & -0.023 & -0.044 & & 0.130 & -0.077 \\
\hline & 0.048 & 0.356 & 0.778 & 0.591 & $\mid \begin{array}{l}0.027 \\
0.741\end{array}$ & 0.114 & 0.347 \\
\hline \multicolumn{8}{|c|}{ Table 4} \\
\hline
\end{tabular}

Correlation is significant at the 0.01 level (2-tailed).

Serum albumin showed a significant positive correlation with T3 and FT3. Bilirubin, prothrombin time and Child-Pugh score showed a significant negative correlation with $\mathrm{T} 3$ and FT3. FT4 showed a negative correlation with serum bilirubin. The best correlation was between FT3 and Child-Pugh score $(-0.658)$. There is no significant correlation between thyroid function and level of liver enzymes (SGOT, SGPT, ALP). TSH did not show any correlation with liver function tests.

\begin{tabular}{|c|c|c|c|c|c|c|}
\hline \multicolumn{7}{|c|}{ Relation between Hepatic Encephalopathy and T3 } \\
\hline & No HE & Grade 1-2 & Grade 3-4 & Total & $\chi^{2}$ & P value \\
\hline $\mathrm{T} 3 \leq 0.8$ & 10 & 13 & 4 & 27 & \multirow{3}{*}{13.31} & \multirow{3}{*}{0.001} \\
\hline T3>0.8 & 90 & 27 & 6 & 123 & & \\
\hline Total & 100 & 40 & 10 & 150 & & \\
\hline \multicolumn{7}{|c|}{ Table 5} \\
\hline
\end{tabular}

Study population was categorised into 3 groups according to the severity of hepatic encephalopathy. In each group, number of patients having T3 level lower than normal range $(0.80-1.81 \mathrm{ng} / \mathrm{mL})$ were found out. Out of the 100 patients who did not show any evidence of HE, 10 had T3 $\leq 0.8$ while 90 patients had $\mathrm{T} 3>0.8$. Of the total of 40 patients with grade 1 - 2 HE, 13 patients (32.5\%) had T3 $\leq 0.8$ and 27 patients had T3 $>0.8(67.5 \%)$, while 4 out of the 10 patients $(40 \%)$ with grade $3-4 \mathrm{HE}$ had T3 $\leq 0.8$ and 6 patients had $\mathrm{T} 3>0.8$ $(60 \%)$. T3 $\leq 0.8$ was present in $10 \%$ of patients without $\mathrm{HE}$ and $32.5 \%$ of patients with grade $1-2 \mathrm{HE}$ and $40 \%$ of patients with grade 3 - 4 HE. This difference was statistically significant with a $P$ value of 0.001 .

\begin{tabular}{|c|c|c|c|c|c|c|}
\hline \multicolumn{7}{|c|}{ Relation between Hepatic Encephalopathy and Free T3 } \\
\hline & $\begin{array}{c}\text { No } \\
\text { HE }\end{array}$ & $\begin{array}{c}\text { Grade } \\
\mathbf{1 - 2}\end{array}$ & $\begin{array}{c}\text { Grade } \\
\mathbf{3 - 4}\end{array}$ & Total & \multirow{2}{*}{$\boldsymbol{\chi}^{\mathbf{2}}$} & P value \\
\cline { 1 - 5 } FT $\leq 2.5$ & 11 & 13 & 4 & 28 & & \\
\cline { 1 - 5 } $3>2.5$ & 89 & 27 & 6 & 122 & \multirow{2}{*}{11.91} & 0.003 \\
\hline Total & $\mathbf{1 0 0}$ & $\mathbf{4 0}$ & $\mathbf{1 0}$ & $\mathbf{1 5 0}$ & & \\
\hline \multicolumn{7}{|c|}{ Table 6} \\
\hline
\end{tabular}


Similarly, in each of the above group, number of patients having Free T3 level lower than normal range (2.50 - 3.90 $\mathrm{pg} / \mathrm{mL}$ ) were also found out. Of the total 100 patients without HE, 11 (11\%) had FT3 $\leq 2.5$, while 89 (89\%) had FT3 > 2.5 . Out of the 40 patients with grade $1-2 \mathrm{HE}, 13$ patients $(32.5 \%)$ had FT3 $\leq 2.5$ and 27 patients had FT3 > $2.5(67.5 \%)$ FT3 $\leq 2.5$ was present in 4 patients $(40 \%)$ with grade $3-4$ HE and FT3 $>2.5$ in 6 patients $(60 \%)$ with grade $3-4$ HE.

FT3 $\leq 2.5$ was present in $11 \%$ of patients without $\mathrm{HE}$ and $32.5 \%$ of patients with grade $1-2 \mathrm{HE}$ and $40 \%$ of patients with grade $3-4$ HE. This difference was statistically significant with a P value of 0.003 .

\begin{tabular}{|c|c|c|c|c|}
\hline & $\begin{array}{c}\text { No Hepatic } \\
\text { Encephalo- } \\
\text { pathy }\end{array}$ & $\begin{array}{c}\text { Grade 1-2 } \\
\text { Hepatic } \\
\text { Encephalo- } \\
\text { pathy }\end{array}$ & $\begin{array}{c}\text { Grade 3-4 } \\
\text { Hepatic } \\
\text { Encephalo- } \\
\text { pathy }\end{array}$ & $\begin{array}{c}\text { One-Way } \\
\text { ANOVA } \\
\text { P value }\end{array}$ \\
\hline TSH & $2.84 \pm 2.37$ & $2.67 \pm 1.29$ & $2.78 \pm 0.76$ & 0.90 \\
\hline T3 & $1.13 \pm 0.30$ & $0.82 \pm 0.20$ & $0.77 \pm 019$ & 0.001 \\
\hline T4 & $7.83 \pm 1.48$ & $7.46 \pm 1.32$ & $7.17 \pm 1.60$ & 0.20 \\
\hline FT3 & $2.97 \pm 1.43$ & $2.46 \pm 0.45$ & $2.21 \pm 0.55$ & 0.001 \\
\hline FT4 & $1.02 \pm 0.21$ & $0.96 \pm 0.20$ & $0.93 \pm 0.19$ & 0.23 \\
\hline \multicolumn{5}{|c|}{ Table 7. Comparison between Thyroid Functions and } \\
\hline \multicolumn{5}{|c|}{ Hepatic Encephalopathy } \\
\hline
\end{tabular}

Thyroid function parameters in patients with no evidence of hepatic encephalopathy and those with grade $1-2$ and grade $3-4$ hepatic encephalopathy were compared using ANOVA. Means of T3 in no hepatic encephalopathy, grade 1 -2 hepatic encephalopathy and grade 3 - 4 hepatic encephalopathy were $1.13 \pm 0.30,0.82 \pm 0.20$ and $0.77 \pm 0.19$ respectively and the difference in means was statistically significant with a p value of 0.001 . Means of FT3 in each above groups were $2.97 \pm 1.43,2.46 \pm 0.45$ and $2.21 \pm 0.55$ respectively and the difference in mean value was found to be significant with a $\mathrm{p}$ value of 0.001 .

\begin{tabular}{|c|c|c|c|c|c|c|}
\hline \multicolumn{7}{|c|}{ Relation between Ascites and T3 } \\
\hline & $\begin{array}{c}\text { No } \\
\text { Ascites }\end{array}$ & Mild & $\begin{array}{c}\text { Moderate-to- } \\
\text { Severe }\end{array}$ & Total & $\chi^{2}$ & P value \\
\cline { 1 - 5 } T3 $\leq 0.8$ & 5 & 16 & 6 & 27 & & \\
\hline T3>0.8 & 69 & 45 & 9 & 123 & 14.055 & 0.001 \\
\hline Total & $\mathbf{7 4}$ & $\mathbf{6 1}$ & $\mathbf{1 5}$ & $\mathbf{1 5 0}$ & & \\
\hline \multicolumn{7}{|c|}{ Table 8 } \\
\hline
\end{tabular}

Study population was grouped according to the severity of ascites. In each group number of patients having T3 level lower than normal range $(0.80-1.81 \mathrm{ng} / \mathrm{mL})$ were found out. Of the total 74 patients without ascites $5(6.8 \%)$ had T3 $\leq 0.8$, while 69 patients $(93.2 \%)$ had T3 $>0.8$. Out of the 61 patients with mild ascites, 16 patients (26.2\%) had T3 $\leq 0.8$ and 45 patients $(73.8 \%$ ) had T3 $>0.8$, while of the 15 patients with moderate-to-severe ascites $\mathrm{T} 3 \leq 0.8$ was present in 6 patients $(40 \%)$ and $\mathrm{T} 3>0.8$ was present in 9 patients $(60 \%)$.

$\mathrm{T} 3 \leq 0.8$ was present in $6.8 \%$ of patients without ascites and $26.2 \%$ of patients with mild ascites and $40 \%$ of patients with moderate-to-severe ascites. This difference was statistically significant with a P value of 0.001 .

\begin{tabular}{|c|c|c|c|c|c|c|}
\hline \multicolumn{7}{|c|}{ Relation between Ascites and FT3 } \\
\cline { 1 - 5 } & $\begin{array}{c}\text { No } \\
\text { Ascites }\end{array}$ & Mild & $\begin{array}{c}\text { Moderate- } \\
\text { to-Severe }\end{array}$ & Total & $\chi^{2}$ & P value \\
\hline FT3 $\leq 2.5$ & 5 & 17 & 6 & 28 & & \\
\cline { 1 - 5 }$>2.5$ & 69 & 44 & 9 & 122 & \multirow{2}{*}{14.81} & 0.001 \\
\hline Total & $\mathbf{7 4}$ & $\mathbf{6 1}$ & $\mathbf{1 5}$ & $\mathbf{1 5 0}$ & & \\
\hline \multicolumn{7}{|c|}{ Table 9 } \\
\hline
\end{tabular}

Similarly, in each group number of patients having Free T3 level lower than normal range $(2.50-3.90 \mathrm{pg} / \mathrm{mL})$ were found out. Of the total 74 patients without ascites, $5(6.8 \%)$ had FT3 $\leq 2.5$, while 69 patients $(93.2 \%)$ had FT3 $>2.5$. Of the total 61 patients with mild ascites, 17 patients $(27.9 \%)$ had FT3 $\leq 2.5$ and 44 patients $(72.1 \%)$ had FT3 $>2.5$, while of the 15 patients with moderate-to-severe ascites FT3 $\leq 2.5$ was present in 6 patients (40\%) and FT3 > 2.5 in 9 patients (60\%). FT $3 \leq 2.5$ was present in $6.8 \%$ of patients without ascites and $27.9 \%$ of patients with mild ascites and $40 \%$ of patients with moderate-to-severe ascites. This difference was statistically significant with a p value of 0.001 .

\begin{tabular}{|c|c|c|c|c|}
\hline & No Ascites & $\begin{array}{c}\text { Mild } \\
\text { Ascites }\end{array}$ & $\begin{array}{c}\text { Moderate-to- } \\
\text { Severe } \\
\text { Ascites }\end{array}$ & $\begin{array}{c}\text { One-Way } \\
\text { ANOVA } \\
\text { P value }\end{array}$ \\
\hline TSH & $2.52 \pm 1.47$ & $3.03 \pm 2.70$ & $3.15 \pm 1.13$ & 0.27 \\
\hline T3 & $1.18 \pm 0.30$ & $0.88 \pm 0.23$ & $0.79 \pm 0.21$ & $\mathbf{0 . 0 0 1}$ \\
\hline T4 & $7.95 \pm 1.45$ & $7.50 \pm 1.37$ & $7.15 \pm 1.62$ & 0.06 \\
\hline FT3 & $3.08 \pm 0.40$ & $2.55 \pm 0.43$ & $2.25 \pm 0.50$ & $\mathbf{0 . 0 0 1}$ \\
\hline FT4 & $1.03 \pm 0.20$ & $0.98 \pm 0.21$ & $0.90 \pm 0.20$ & 0.08 \\
\hline \multicolumn{5}{|c|}{ Table 10. Comparison between Thyroid Functions and } \\
Ascites \\
\hline
\end{tabular}

Thyroid function parameters in ascites were compared using ANOVA. Means of T3 in no ascites, mild ascites and moderate-to-severe ascites group were $1.18 \pm 0.30,0.88 \pm$ 0.23 and $0.79 \pm 0.21$ respectively and the difference in means was statistically significant with a $p$ value of 0.001 . Means of FT3 in each of the above groups were $3.08 \pm 0.40,2.55 \pm 0.43$, $2.25 \pm 0.50$ respectively and the difference in mean value was found to be significant with a p value of 0.001 .

\begin{tabular}{|c|c|c|c|c|c|c|}
\hline \multicolumn{7}{|c|}{ T3 and Child-Pugh Score } \\
\cline { 1 - 5 } & CPSA & CPSB & CPSC & Total & $\chi^{2}$ & P value \\
\hline T $3 \leq 0.8$ & 1 & 6 & 20 & 27 & & \\
T $3>0.8$ & 32 & 40 & 51 & 123 & \multirow{2}{*}{10.75} & 0.005 \\
\cline { 1 - 5 } Total & 33 & $\mathbf{4 6}$ & $\mathbf{7 1}$ & $\mathbf{1 5 0}$ & & \\
\hline \multicolumn{7}{|c|}{ Table 11 } \\
\hline
\end{tabular}

The study population was categorised according to the severity of liver dysfunction assessed by Child-Pugh score as CPS A, CPS B, CPS C and number of patients having T3 level lower than normal range $(0.80-1.81 \mathrm{ng} / \mathrm{mL})$ were found out. Of the total 33 patients with CPS A, 1 patient $(3.03 \%)$ had $\mathrm{T} 3 \leq 0.8$, while 32 patients $(96.97 \%)$ had $\mathrm{T} 3>0.8$. Of the total of 46 patients with CPS B, 6 patients $(13.04 \%)$ had T3 $\leq 0.8$ and 40 patients $(86.96 \%)$ had $\mathrm{T} 3>0.8$, while of the 71 patients with CPS C T3 $\leq 0.8$ was present in 20 patients $(28.2 \%)$ and $\mathrm{T} 3>0.8$ in 51 patients $(71.8 \%)$.

T3 $\leq 0.8$ was present in $3.03 \%$ of patients with CPS A and $13.04 \%$ of patients with CPS B and $28.2 \%$ of patients with CPS C. Number of patients with a T3 level lower than normal 
range $(0.80-1.81 \mathrm{ng} / \mathrm{mL})$ significantly increased ( $\mathrm{p}$ value of 0.005) along with Child-Pugh scores A, B and C.

\begin{tabular}{|c|c|c|c|c|c|c|}
\hline \multicolumn{7}{|c|}{ Free T3 and Child-Pugh Score } \\
\cline { 1 - 5 } & CPSA & CPSB & CPSC & Total & $\chi^{2}$ & P value \\
\cline { 1 - 5 } FT $\leq 2.5$ & 1 & 7 & 20 & 28 & & \\
FT3>2.5 & 32 & 39 & 51 & 122 & \multirow{2}{*}{ Table 12 } \\
\hline Total & 33 & $\mathbf{4 6}$ & $\mathbf{7 1}$ & $\mathbf{1 5 0}$ & & 0.007 \\
\hline \multicolumn{7}{|c|}{} \\
\hline
\end{tabular}

Similarly, number of patients having Free T3 level lower than normal range $(2.50-3.90 \mathrm{pg} / \mathrm{mL})$ were found out in each CPS group and following observations were made of the total 33 patients in CPS A group. One patient (3.03\%) had FT3 $\leq 2.5$, while 32 patients $(96.97 \%)$ had FT3 $>2.5$. Of the total of 46 patients in CPS B group, 7 patients $(15.2 \%)$ had FT3 $\leq 2.5$ and 39 patients $(84.8 \%)$ had FT3 $>2.5$, while of the 71 patients with CPS C. FT $3 \leq 2.5$ was present in 20 patients $(28.2 \%)$ and $\mathrm{FT} 3>2.5$ was present in 51 patients $(71.8 \%)$.

FT3 $\leq 2.5$ was present in $3.03 \%$ of patients with CPS A and $15.2 \%$ of patients with CPS B and $28.2 \%$ of patients with CPS C. Number of patients with a Free T3 level lower than normal range significantly increased ( $p$ value of 0.007 ) along with Child-Pugh scores A, B and C.

\begin{tabular}{|c|c|c|c|c|}
\hline & CPS A & CPS B & CPS C & $\begin{array}{c}\text { One-Way ANOVA } \\
\text { P value }\end{array}$ \\
\hline TSH & $3.37 \pm 1.46$ & $2.13 \pm 12.67$ & $2.94 \pm 1.70$ & 0.18 \\
\hline T3 & $1.26 \pm 0.26$ & $1.06 \pm 0.27$ & $0.87 \pm 0.27$ & 0.001 \\
\hline T4 & $7.98 \pm 1.33$ & $7.78 \pm 1.53$ & $7.69 \pm 1.45$ & 0.24 \\
\hline FT3 & $3.17 \pm 0.35$ & $2.94 \pm 0.43$ & $2.78 \pm 0.52$ & 0.001 \\
\hline FT4 & $0.99 \pm 0.11$ & $1.04 \pm 0.25$ & $0.99 \pm 0.20$ & 0.195 \\
\hline \multicolumn{4}{|c|}{ Table 13. Comparison between Thyroid Functions } \\
and Child-Pugh Score \\
\hline \multicolumn{4}{|c|}{} \\
\hline
\end{tabular}

Thyroid function parameters in each Child-Pugh group were compared using ANOVA. Means of T3 in CPS A, CPS B and CPS $C$ were $1.26 \pm 0.26,1.06 \pm 0.27$ and $0.87 \pm 0.27$ respectively and the difference in means was statistically significant with a p value of 0.001 . Means of FT3 in CPS A, CPS $\mathrm{B}$ and $\mathrm{CPS} \mathrm{C}$ were $3.17 \pm 0.35,2.94 \pm 0.43,2.78 \pm 0.52$ respectively and the difference in mean value was found to be significant with a $\mathrm{p}$ value of 0.001 .

\section{DISCUSSION}

\section{Following Observations were made in this Study}

\section{i. Age Group}

In this study, majority of patients with chronic liver disease were among the age group of 41 to 49 years (54.7\%). mean age was $48.27 \pm 6.57$ years. This was comparable to the study done by Mansour-Ghanaei $\mathrm{F}$ et $\mathrm{al},{ }^{1}$ in which mean age was $55.03 \pm 12.05$ years

\section{ii. Gender}

In this study, 124 patients (83\%) were males and 26 were females $(17 \%)$. The study conducted by Borzio et al had $87 \%$ male population. ${ }^{2}$

\section{iii. Thyroid Dysfunction in Study Population}

37 patients $(24.6 \%)$ showed abnormal thyroid function parameters. 113 patients were euthyroid. Commonest thyroid dysfunction was sick euthyroid syndrome in 27 patients (18\%) followed by subclinical hypothyroidism in 7 patients $(4.7 \%)$. These results were comparable to the study conducted by Sandeep Kharb ${ }^{3}$ et al, which showed that $16 \%$ of patients with liver disease had thyroid dysfunction in which $7 \%$ had sick euthyroidism, 3.5\% had subclinical hyperthyroidism.

\section{iv. Correlation between Thyroid Function Parameters and Liver Function Indices}

In this study, serum T3 and FT3 levels showed significant positive correlation with serum albumin level ( $\mathrm{p}$ value < 0.05 ) and significant negative correlation with serum bilirubin level, INR value and Child-Pugh score ( $p$ value $<0.05$ ). FT3 showed highest correlation between liver function indices, maximum with Child-Pugh score. Borzio et al in their study observed that serum T3 is significantly correlated with serum bilirubin, albumin, prothrombin time and serum T3 levels appear parallel to the severity of liver dysfunction. Sandeep Kharb et al showed a significant decrease in T3 and FT3 in liver disease according to severity assessed by the Child-Pugh staging. ${ }^{3}$ Novis et al also observed a positive relationship between the low serum levels of T3 with the degree of hepatic dysfunction according to the ChildPugh classification. ${ }^{4}$ Green JR et al observed an increased TSH response in hepatic cirrhosis patients. 5

\section{v. Thyroid Function and Ascites}

In this study, T3 and FT3 levels were significantly reduced in patients who had ascites.

\section{vi. Thyroid Function Abnormalities and Hepatic Encephalopathy}

In this study, T3 and FT3 were significantly reduced ( $\mathrm{p}$ value $<0.01$ ) in those patients with hepatic encephalopathy. Kayacetin et al found a significant reduction in serum FT3 in non-alcoholic cirrhotic patients compared with a control group. ${ }^{6}$ El-Sawy et al also demonstrated a significant reduction of FT3 level in patients with hepatic encephalopathy in patients with chronic hepatitis $\mathrm{C}$ related liver cirrhosis. ${ }^{7}$ These results suggest that serum T3 and FT3 may be considered a sensitive index of hepatic function in liver disease.

According to Oren $\mathrm{R}$ et al, hypothyroidism in cirrhotic patients has been shown to be associated with a biochemical improvement in liver function and a decreased rate of decompensation in chronic liver disease. ${ }^{8}$

\section{CONCLUSION}

1. Chronic liver diseases were associated with abnormalities in thyroid function tests, although most of the patients remained clinically euthyroid.

2. Serum T3 and FT3 levels had an inverse correlation with the severity of liver dysfunction.

\section{Limitations of the Study}

1. It was a cross-sectional study without follow-up of the patients. A cohort study would have been better for assessing the prognosis of patients with chronic liver diseases with regard thyroid function tests.

2. Assessment of liver disease was limited by lack of histological diagnosis. 


\section{Recommendations}

- $\quad$ Serum T3 and FT3 concentrations may be considered as a sensitive index of hepatic function in chronic liver disease.

- Thyroid hormone is an important determinant of basal metabolic rate, low total and free $\mathrm{T} 3$ levels in chronic liver diseases may reflect the adaptive hypothyroid state which reduces the basal metabolic rate and helps to preserve hepatocytes and liver function. Hence, treatment indication of hypothyroidism in chronic liver disease has to be redefined.

\section{REFERENCES}

[1] Mansour-Ghanaei F, Mehrdad M, Mortazavi S, et al. Decreased serum total T3 level in hepatitis B and C related cirrhosis by severity of liver damage. Ann Hepatol 2012;11(5):667-71.

[2] Borzio M, Caldara R, Borzio F, et al. Thyroid function tests in chronic liver disease: evidence for multiple abnormalities despite clinical euthyroidism. Gut 1983;24(7):631-6.

[3] Kharb S, Garg MK, Puri P, et al. Assessment of thyroid and gonadal function in liver diseases. Indian J Endocrinol Metab 2015;19(1):89-94.
[4] Novis M, Vaisman M, Coelho HSM. Thyroid function tests in viral chronic hepatitis. Arq Gastroenterol 2001;38(4):254-60.

[5] Green JR, Snitcher EJ, Mowat NA, et al. Proceedings: Anomalous TSH secretion in liver disease: further evidence of hypothalamic-pituitary dysfunction. Gut 1976;17(5):395-6.

[6] Kayacetin E, Kisakol G, Kaya A. Low serum total thyroxine and free triiodothyronine in patients with hepatic encephalopathy due to non-alcoholic cirrhosis. Swiss Med Wkly 2003;133(13-14):210-3.

[7] El-Sawy AA, Tawfik MAER. Low serum free and total triiodothyronine hormones as possible prognostic factors in liver cirrhotic patients due to chronic hepatitis C. Thyroid Res Pract 2015;12(3):87-92.

[8] Oren R, Hilzenrat N, Maaravi Y, et al. Hemodynamic effects of hypothyroidism induced by methimazole in normal and portal hypertensive rats. Dig Dis Sci 1995;40(9):1941-5. 